\title{
PUBLIC HEALTH AND HEALTH CARE
}

\author{
UDC 614.253.52:331.108.2
}

\section{About the problem of personnel management in healthcare (on nursing staff example)}

\author{
N. G. Petrova, S. G. Pogosyan \\ Pavlov First St. Petersburg State Medical University, \\ 6-8, ul. L'va Tolstogo, St. Petersburg, 197022, Russian Federation
}

For citation: Petrova N.G., Pogosyan S. G. About the problem of personnel management in healthcare (on nursing staff example). Vestnik of Saint Petersburg University. Medicine, 2020, vol. 15, issue 3, pp. 203-207. https://doi.org/10.21638/spbu11.2020.305

It is noted in the article that the problem of nursing staff shortage is relevant to all health-
care organizations. According to the study performed in the basic institutions (the municipal
hospital and polyclinic) the staffing level is about $70 \%$ without large changes in dynamics.
In addition, a significant portion of nurses (especially in the polyclinic) are the persons of
pre-retirement and retirement age. Only $28.9 \%$ of nurses did not think about the possibility
of changing the location and nature of their work. The factors that can affect the ability to at-
tract and retain personnel were analyzed using the nurses' survey. It was found that $82.2 \%$ of
respondents believe that their workload is high; $58.3 \%$ of them told that their work does not
fully correspond to the functional responsibilities. There are the problems in the relationship
in the team (including doctors and managers). Respondents consider that it is necessary to
improve the organization of the labor process in the institution, the system of wage and moti-
vation as a whole, to work for increasing the prestige of the profession. A number of measures
aimed to improve the personnel management in health care organization are proposed. Keywords: personnel management, nursing staff, motivation.

\section{Introduction}

In conception of health care system development of Russian Federation till $2020^{1}$ was stated, that one of its backborne factors, necessary for its efficient functioning, is availability of sufficient number of properly trained medical personnel, capable to solve all

${ }^{1}$ The Decree of the President of the Russian Federation "On the strategy of health care development in the Russian Federation for the period up to 2025”. Available at: http://docs.cntd.ru/document/554815875 (accessed: 17.12.2020. (In Russian)

(C) St. Petersburg State University, 2020 
the tasks in hand. Human resourcing of the health care system recently is one of the most actual problems. That problem includes the following constituents ${ }^{2}[1 ; 2]$ : availability of personnel, their optimal relationship (by specialties, positions, types of medical organizations), high level of professional training, motivation to efficient labor. From the viewpoint of personnel availability the most acute recently is a problem associated with deficit of paramedical personnel actually in all the spheres of health care system and the country regions [3; 4]. More over, it is rather actual for all the other countries as well [5]. This problem in many respects is associated with such factor as low, irresponsive to physical and psycho-emotional expenditures, pay level, insufficient prestigiousness of profession, absence in many cases opportunity of professional growth and self-perfection, leading to dissatisfaction and disappointment, outdated medical and organizational technologies of nurse business [6]. Preparation and continuous professional upgrade of medical personnel is not less complex task, that, in its turn, is determined by availability of respective material and technical resources and professional level of teachers of higher and secondary vocational medical education system, by organization and content of educational programs and educational process, it correspondence to scientific achievements and practice needs and other conditions [7].

Purpose of the recent study: to study demographic composition of nurses at different types of medical organizations, level and factors of its motivation to labor and to propose measures on enhancement personnel management in medical organizations.

\section{Material and methods}

As a basis for investigation we select: municipal multidisciplinary clinic and municipal multidisciplinary hospital. Survey questionnaire among nurses was carried out (desk nurses, treatment nurses, district nurses and head nurses of different departments) using specially developed inquiry form. Total number of respondents constituted 120 persons (necessary to provide representativeness number of observations, calculated by special formula, constituted 80). Inquiry form included questions of opened and closed types. All the respondents were guaranteed (and was ensured) full anonymity, that enables to suppose sincerity of expressed judgments. Obtained data were processed at personnel computer with application "Statistica 6" program and MS Excel. Extensive and intensive indicators and their errors were calculated. Confidence of indicator differences were determined by means of Student's test application.

\section{Results and their discussion}

Performed analysis demonstrated, that the problem of staffing level of nurses is actual for municipal clinic and for hospital as well. So, percentage of staffing level in its dynamics (2011-2016) does not exceed $72 \%$. Age structure of the stuff differs in these organizations being more "elderly" in municipal clinic. So, portion of persons at age 50 years and older constituted there $39.2 \%$, and a portion of personnel at age younger than 30 years only $10.9 \%$. Among those who worked in hospital ratio of personnel of the old age group constituted $26.6 \%$, and persons younger than 30 years $-35.4 \%$. The differences of pro-

2 The program of development of nursing in Russia in 2010-2020. Available at: www.sisterflo.ru/ nurse-docs/nursing-program.php (accessed: 18.06.2017). (In Russian) 
vided indicators are significant $(\mathrm{p}>0.05)$ and related to the following circumstances. As it was demonstrated by previously performed investigation [8], being educated in medical college, considerable part (38.5\%) of students has intension after graduation to work in hospital, than in clinic (15.0\%). That is why replenishment of clinic staff composition by young personnel is rather actual problem. Besides, gross staff rotation is appropriate to hospitals (especially to departments and specialties with high workload level, necessitating personnel to look for more optimal working conditions, especially at old age). Partially it is confirmed by the results of our investigation. So, on the question about intension to change the work most people (66.7\%) who worked in hospital, answered that this desire sometime arise in them; $4.4 \%$ had this intension at the moment of the study performance ( $28.9 \%$ never had the desire to change the work). The greatest percent of respondents among nurses, who sometimes feel the desire to change the work, were at neurological department (80.0\%).

Among those, who worked in municipal clinic, $64 \%$ of respondents had 10 years of service as a nurse, among those who worked in hospital $-68.0 \%$; percentage of those who had 3 years of service constituted respectively 16.0 and $10.6 \%$. Despite of practically equal percentage of personnel whose service live exceeded 10 years, $56.1 \%$ of respondents in municipal clinic had no qualification grade, while among the personnel in hospital those who had no qualification grade constituted $28.1 \%$ (predominately young specialists), that may be associated with less interest of those who worked in municipal clinic to receive it.

Effort to attract as well as to «retain» personnel mostly depends from availability and expressivity of different motivating and de-motivating labor factors. In course of questionnaire survey respondents were proposed a number of questions concerning their estimate. Overwhelming majority (82.2\%) of nurses estimated degree of their workload as high ( $11.1 \%$ considered it normal, the rest did not answered this question). More over, indicating the reasons, effecting the quality of provided nursing, $56.3 \%$ of respondents noticed high workload. The next reason, singled out by $22.4 \%$ respondents, was called inconsistence in the work of medical personnel. At that it is necessary to point out, that important factor of non-material personnel motivation is psycho-emotional climate in staff community. Answering the question about arising problems in interrelation between doctors and nurses, $48.9 \%$ indicated that such problems sometimes appeared. Despite that, $80.0 \%$ of medical nurses pointed out, that they are quite satisfied with their relations with doctors (15.6\% - satisfied not entirely, $4.4 \%$ did not answer this question). $74.4 \%$ of respondents pointed out, that these relations are influenced by a work environment as a whole; $34.1 \%$ - working experience; $29.3 \%$ - "status". Undoubtedly, the term working environment is rather complex. It includes presence of clear process organization inside department (its structuring at separate sub-processes and operations with concretization of functional duties for each employee), communication inside organization, good material and technical resources, ergonomics of labor conditions and so on. Let us note in this connection, that major portion ( $58.3 \%$ of respondents) considered, that their functional duties only partially match with actually performing work (that also can may be a source of conflicts in staff community). That is, creation of optimal organizational conditions for work, among others, is a factor psychological stability inside the staff community, forming optimal material dealings of doctors and nurses. At the same time, managers of medical organizations and separate departments should pay attention, that relation of some doc- 
tors to nurses is suffered from insufficiently correct, to our mind, understanding their status in staff community, admitted to solve general and complementary tasks.

It should not left unnoticed that on the question about whether in staff community occure conflicts, positively answered $66.6 \%$ of respondents among medical nurses, including $2.2 \%$ who noted very often conflict occurring $(24.4 \%$ answered negatively and $8.9 \%$ can not answer at all). Most frequently the cause of conflicts respondents considered misunderstanding between personnel (24.4\%) and high workload (24.4\%); $11.1 \%$ pointed out "gossips"; $4.4 \%$ - "displacement of duties"; 2,2\% — insufficient professional skill.

Relationship in staff community to a large extent depends on position of its manager. $62.2 \%$ respondents pointed out, that they feel support from the manager; $26.7 \%$ - feel it "not always"; $8.9 \%$ - does not feel the support ( $2.2 \%$ prefer not to answer).

Respondents were proposed in arbitrary form to point out, which of the factors are the most significant for increasing level of motivation in their activity. $53.4 \%$ percents consider necessary to improve material and technical resources; one in three (33.3\%) consider necessary to improve wages, development of new (understandable and "transparent") system of material encouragement, increasing qualification of middle and junior medical personnel; $20.0 \%$ consider important formation of motivation system as a whole; rarely other proposals were expressed.

\section{Conclusions}

Thereby, performed study demonstrated, that the problem of medical institutions staffing by nurses is actual for municipal clinics (at higher degree) and for hospitals as well. That problem bear multifunctional character and its solution is impossible without systematic implementation of the staff managing measures (which must be deal by the managers of these organizations, nursing managers, personnel managers). Already at the planning stage it is necessary to clearly distribute functional duites not only for all cetegories of medical personnel (and even for separate groups), but also for certain employee, which must be continuously corrected with consideration of changing medical and organizational technologies. Accounting to modern concepts of medical assistance quality management, personnel should be actively involved in management processes (development of personnel and group aims, algorithms of processes performance and their results estimation, provision of resultant group activity, system of motivation, planning carrier promotion and staff reserve formation).

Systematic analysis of staff needs by means of open double sided exchange of information and ascertainment of personnel satisfaction degree by their work in the given medical organization. Staff must be informed about their proposals implementation. It is necessary to provide monitoring and analysis of the reason of personnel arrival into organization and leaving it.

Staff politics must include three mutually related directions:

- planning and optimization of staff number and staff structure;

- improvement of personnel training (continuous education, creation the possibility for training at the working place, including opening learning and teaching centers or cabinets on the base of organization, attracting to participate in scientific conferences, interaction with educational organizations at selecting staff and upgrading their qualification); 
- managing human resources (including above mentioned aspects and provision legal and social protection for personnel, increasing efficiency of the labor safety measures and security, conflict management, creation favorable psychological climate, formation style of management answering the purposes of the organization and staff community structure, purposeful work on increasing prestigiousness of the work of all medical staff categoris).

Especially it is necessary to dwell on questions of improvement personnel wages system. Categories of wages distribution should foresee application in the work advanced technologies, novel methods; outdoor service; degree of stress in labor; special regime of work, associated with the necessity of prompt solution of new or current tasks; high achievements in the work, performance of especially important or urgent work. The size of stimulating payments must be differentiated for departments and services with consideration coefficient of completeness, complexity of performed works, level of staff qualification, summer holiday period. Each department should develop and approved list of rising and lowering coefficients, affecting the size of personnel reward.

\section{References}

1. Vyalkov A.I. Management of healthcare of the Russian Federation. Theory and practice. Moscow, GEOTAR-MED Publ., 2013. 528 p. (In Russian)

2. Petrova N. G., Pogosyan S. G. To the question about the formation of nurses' work motivation. Actual problems of health and medical education: proceedings of the conference dedicated to the memory of Professor I. V. Polyakov. Ed. by prof. G. Petrova. St. Petersburg, 2014, pp. 138-142. (In Russian)

3. Grekova I.I. To the question about making up for manpower nurses' resource. Problems of social hygiene, healthcare and history of medicine, 2013, no. 2, pp. 38-40. (In Russian)

4. Fetisova I. Personnel shortage - solutions to the problems. Nursing, 2014, no. 3, pp. 24-25. (In Russian)

5. Najafi F., Fallahi-Khoshnab M., Ahmadi F., Dalvandi A., Rangozar M. Human dignity and professional reputation under threat: Iranish nurses' experience of workplace violence. Nursing and health sciences, 2017, vol. 19, no. 1, pp.44-50.

6. Nazarenko L. I., Pakhomov N. A. Technology nursing process management in health care organizations. Doctor, 2015, no. 5, pp. 41-50. (In Russian)

7. Petrova N. G., Soboleva N. I. Modern problems of nurses' training. Scientific notes of Saint-Petersburg I. P. Pavlov State Medical University, 2010, vol. 17, no. 3, pp. 27-30. (In Russian)

8. Petrova N.G. Actual problems of nurses' training. Actual problems of health and medical education: proceedings of the conference dedicated to the memory of Professor I. V. Polyakov. St. Petersburg, 2014, pp. 134-136. (In Russian)

Received: November 10, 2020 Accepted: December 15, 2020

Authors' information:

Nataliya G.Petrova - PhD, Professor; petrova-nataliya@bk.ru

Sarkis G.Pogosyan — PhD; nursingdep@mail.ru 